\title{
O golpe de 2016 e os impactos para a educação superior brasileira
}

\author{
Deise Mancebo
}

Universidade do Estado do Rio de Janeiro

\section{Resumo}

artigo discute os principais impactos da complexa conjuntura brasileira nas políticas para a educação superior, com especial destaque aos acontecimentos econômicos e políticos que tiveram curso após o golpe de 2016. É um estudo de caráter exploratório e sua construção apoia-se em pesquisa bibliográfica, na análise documental de problemáticas necessárias para a compreensão do tema, na consulta à legislação pertinente e no levantamento e discussão de estatísticas existentes, adotando, portanto, uma perspectiva de análise que conjuga aspectos quantitativos e qualitativos. Seu desenvolvimento ocorre em dois momentos: (1) uma breve discussão da complexa conjuntura econômica e políitica na qual o país se encontra envolvido, considerando o retorno de forte ofensiva conservadora e (2) uma análise da educação superior nesse contexto, subdividida, por seu turno, nos impactos diferenciados que se pode observar na rede pública e na rede privado-mercantil. Conclui, enumerando alguns desafios para a superação da atual conjuntura e para a defesa da educação pública.

Palavras-chave: Golpe de 2016. Políticas da educação superior. Rede pública. Rede privada.

\section{The coup of 2016 and the impacts on Brazilian higher education}

\section{Abstract}

The article discusses the main impacts of the complex Brazilian context on higher education policies, with special emphasis on the economic and political events that took place after the coup of 2016 . It is an exploratory nature study and its construction is based on bibliographic research, in documentary analysis of problems necessary to understand the topic, in consulting the relevant legislation and in the collection and discussion of existing statistics, adopting, therefore, a perspective of analysis that combines quantitative and qualitative aspects. Its development occurs in two moments: (1) a brief discussion of the complex economic and political conjuncture in which the country is involved, considering the return of a strong conservative offensive and (2) an analysis of higher education in this context, subdivided, in turn, into the differentiated impacts that can be observed in the public network and in the private-commercial network. It concludes by enumerating some challenges for overcoming the current situation and for the defense of public education.

Keywords: Coup of 2016 . Policies of higher education. Public education. Private education. 


\section{El golpe de 2016 y los impactos para la educación superior brasileña}

\section{Resumen}

El artículo discute los principales impactos de la compleja coyuntura brasileña en las políticas para la educación superior, con especial destaque a los acontecimientos económicos y políticos que tuvieron curso después del golpe de 2016. Es un estudio de carácter exploratorio y su construcción se apoya en investigación bibliográfica, en el análisis documental de problemáticas necesarias para la comprensión del tema, en la consulta a la legislación pertinente y en el levantamiento y discusión de estadísticas existentes, adoptando, por lo tanto, una perspectiva de análisis que conjuga aspectos cuantitativos y cualitativos. Su desarrollo se lleva a cabo en dos etapas: (1) una breve discusión de los complejos acontecimientos económicos y políticos en los que el país está involucrado, teniendo en cuenta el retorno de fuerte ofensiva conservadora y (2) un análisis de la educación superior en este contexto, subdividido, a su vez, en los impactos diferenciados que se pueden observar en la red pública y en la red privado-mercantil. Concluye, enumerando algunos desafíos para la superación de la actual coyuntura y para la defensa de la educación pública.

Palabras clave: Golpe de 2016 . Políticas de la educación superior. Red pública. Red privada..

\section{Introdução}

$\bigcirc$ presente texto, apresentado em uma versão preliminar na Universidade Federal do Rio Grande do Norte', pretende discutir os principais impactos da complexa conjuntura brasileira atual nas políticas para a educação superior. É um estudo de caráter exploratório e sua construção apoia-se em pesquisa bibliográfica, análise documental de problemáticas, necessárias à compreensão do tema e na consulta de estatísticas existentes, adotando, portanto, uma perspectiva de análise que conjuga aspectos quantitativos e qualitativos.

Seu desenvolvimento ocorre em dois momentos: (1) uma breve discussão da complexa conjuntura econômica e política na qual o país se encontra envolvido e (2) uma análise da educação superior nesse contexto, subdividida, por seu turno, nos impactos diferenciados que podem ser observados na rede pública e na rede privada.

Deve-se registrar que boa parte das fontes e das análises apresentadas pertence a um coletivo de mais de 300 pesquisadores da Rede Universitas/ $\mathrm{Br}$, que participam do projeto integrado "Políticas, gestão e direito à educação superior: novos modos de regulação e tendências em construção". A eles, 
pertence boa parte dos dados e comentários expostos, mesmo que as conclusões, eventualmente apressadas, sejam nossas.

\section{A complexa conjuntura brasileira atual e o golpe de 2016}

Os dilemas da educação no Brasil encontram-se absolutamente imbricados com a complexa conjuntura econômica e política vivida no país, particularmente, a educação superior.

O pano de fundo dessa conjuntura é a crise econômica internacional, cujo marco foi o ano de 2008. A violência dessa crise tem provocado um realinhamento entre as diferentes frações do capital, dentro e fora do país; e também um realinhamento de forças entre os diferentes Estados, em âmbito mundial. Seus impactos manifestam-se de forma diferenciada em termos geográficos e temporais, mas é inegável que, no último período, impactou com força a periferia do sistema e suas condições para a acumulação de capital, criando e intensificando contradições insuperáveis, que, por um lado, reduziram as taxas de lucro, a competitividade, e terminaram por constituir obstáculo

64 à própria continuidade da acumulação do capital; por outro, têm produzido aumento significativo da expropriação sobre os trabalhadores, ampliado o desemprego ${ }^{2}$, precarizado os postos de trabalho restantes, reduzido salários, intensificado a jornada de trabalho. Simultaneamente, assiste-se a uma ofensiva contra as condições de vida e de luta das classes subalternas, com o sucateamento dos serviços públicos (educação, saúde, saneamento, abastecimento, transportes) e o reforço do aparelho repressivo de Estado, ampliando, sobremodo, as desigualdades estruturais.

Obviamente, cada país tem sua própria história, irredutível e única, no entanto, os episódios políitico-econômicos, ocorridos nos últimos tempos, confirmam que as diferenças, que são relevantes, convivem, na América Latina, com imensas semelhanças, entre as quais:

a) nossas classes dominantes preferem subordinar-se [ao capital internacional] do que construir experiências democráticas e progressistas de desenvolvimento soberano;

b) nossas classes dominantes e seus representantes políticos [jurídicos] e midiáticos têm com a democracia uma relação meramente instrumental e 
c) nossas classes dominantes preferem ganhar dinheiro por meio da desigualdade e da dependência às metrópoles, do que por intermédio da integração regional [e da promoção da igualdade] (POMAR, 2016, p. 16).

No Brasil, foram abaladas as próprias bases sociais da reprodução política, cujo destaque foi o impeachment da presidenta eleita Dilma Rousseff, ocorrido em 31 de agosto de 2016, sem prova material e cabal e, mais recentemente, a condenação e prisão do ex-presidente Luiz Inácio Lula da Silva (em 7 de abril de 2018), numa tentativa de retirar o ex-presidente da disputa eleitoral de 2018, e seguir com um governo cuja única lealdade é com as contrarreformas e os interesses do grande capital. Somando-se a esses dois fatos diversos, outros acontecimentos e, em especial, a recente intervenção militar no Estado do Rio de Janeiro, tem-se, indiscutivelmente, a constituição, no país, de um verdadeiro Estado de Exceção, como o define Agamben $(2004)^{3}$, e de uma ordem abertamente autoritária, atropelando as ilusões de quem acreditava nas virtudes infinitas da política de conciliação de classes, qual seja, a ideia de que seria possível superar o apartheid social e o subdesenvolvimento no Brasil sem confronto com as elites dominantes, mas apenas por meio do crescimento da economia (SINGER; LOUREIRO, 2016).

Em suma, desde 2016, o Brasil amarga um golpe, uma ruptura democrática, acompanhada por uma grave crise política, econômica e social, com todos os requintes de uma plataforma programática do neoliberalismo extremado (MANCEBO, 2017).

De modo geral, tal plataforma - sintetizada no documento "Uma ponte para o futuro" (Partido do Movimento Democrático Brasileiro [PMDB], 20 15) - indica a rendição ao ciclo do capital financeiro, com duas consequências estruturais:

(1) a redução fantástica do custo do trabalho vivo, de que é prova(a) a aprovação da Lei no 13.429, de 31 de março de 2017 (BRASIL, 2017)que garante, entre outros aspectos, a terceirização irrestrita;(b) a aprovação da Lei no 13.467, de 13 de julho de 2017 (BRASIL, 2017), ou Reforma Trabalhista, cuja essência das mudanças diz respeito à afirmação do negociado sobre - legislado, à flexibilização da jornada de trabalho, à introdução de novas modalidades de contratação - como o trabalho intermitente, por exemplo -, e à ameaça à garantia de gratuidade do processo trabalhista e (c) a Proposta 
de Emenda Constitucional n 287 de 5 de dezembro de 2016 (BRASIL, 2016) e seus substitutivos, conhecida como a Reforma da Previdência.

(2) a reforma do Estado, fazendo-o deixar espaço para os interesses geopolíticos internacionais - em especial, os interesses norte-americanos relacionados à produção e distribuição de petróleo - e para o oferecimento do fundo público ao capital financeiro.

Retomando os termos do documento, "Uma ponte para o futuro" (PMDB, 2015) defende a tese central de que se gasta muito com políticas públicas, fazendo-se necessário um equilíbrio fiscal por meio de corte dos gastos públicos. $\bigcirc$ governo de Michel Temer e o Congresso Nacional têm se dedicado à aplicação dessa cartilha, garantindo os privilégios do capital financeiro/especulativo e adotando medidas que aprofundam a expropriação dos direitos sociais e a destruição do serviço público, como foi o caso da Emenda Constitucional no 95, de 16 de dezembro de 2016 (BRASIL, 2016), a partir da qual, foram inseridos, nas Disposições Constitucionais Transitórias, vários dispositivos que implementaram um novo regime fiscal com um limite para os gastos do governo federal, que vigorará pelos próximos 20 (vinte) anos. $\bigcirc$ teto de gastos, fixado para 2017, corresponde ao orçamento disponível para 66 os gastos de 2016 , acrescido da inflação daquele ano. Para a educação e a saúde, o ano-base será o de 2017, com início de aplicação em 2018.

As regras do novo regime não permitem, assim, o crescimento das despesas totais e reais do governo acima da inflação, nem mesmo se a economia estiver bem, o que diferencia o caso brasileiro de outras experiências estrangeiras que adotaram o teto de gastos públicos. Somente será possível aumentar os investimentos em uma área desde que sejam feitos cortes em outras. As novas regras desconsideram, portanto, as taxas de crescimento econômico, como também as demográficas pelos próximos 20 (vinte anos), o que (e aqui já antecipando a nossa crítica a respeito), poderá levar ao sucateamento das políticas sociais, especialmente nas áreas da saúde e educação, pondo em risco por completo a qualidade de vida da população brasileira (MARIANO, 2017, p. 261).

Em termos bem gerais, "Uma ponte para o futuro" é um programa político-econômico que pretende, de um lado, aprofundar o papel de um "Estado mínimo" para realizar o benefício social e que, de outro, é suficientemente forte para incrementar a participação da iniciativa privada, flexibilizar o mercado 
de trabalho e ampliar a concorrência internacional, abrir de maneira escancarada as portas para a venda do patrimônio nacional, suprimindo liberdades e até aprisionando.

Essa "Ponte para o futuro" (PMDB, 2015), cuja concretização já se encontra bastante avançada em seus aspectos normativos, significa um forte retrocesso nos direitos inscritos na Constituição de 1988, nas conquistas mesmo que insuficientes alcançadas nos governos liderados pelo Partido dos Trabalhadores (PT), desde 2003, e até nas conquistas da "Era Vargas" (MANCEBO, 2017).

\section{Conservadorismo e autoritarismo}

A conjuntura complexifica-se com uma forte ofensiva conservadora, com graves traços fascistizantes, tais como:

[...] a intolerância religiosa, o irracionalismo, o anticomunismo, o nacionalismo vazio de elementos minimamente progressistas, a homofobia, o machismo e outras manifestações que capturam para uma lógica reacionária o descontentamento com as instituições (IASI, 2017, p. 1-2).

As forças que encabeçam o conservadorismo - o Movimento Brasil Livre-MBL, militaristas e religiosos fundamentalistas, principalmente - têm equipes profissionalizadas e implementam ações diversas sobre a sociedade, como: uma crescente violência, simbólica e física, contra grupos socialmente excluídos; uma ampla explicitação de casos de discriminação de minorias sociais, com ênfase sobre relações homoafetivas; uma intolerância manifesta de cunho religioso, visivelmente contra expressões religiosas de base etnocultural indígena e africana; atitudes manifestas contra a liberdade de expressão, nos mais diversos espaços; ações legislativas para impor uma Escola dita sem Partido ${ }^{4}$, mas nitidamente de cunho religioso criacionista, de base evangélica de mercado, contra princípios culturais e científicos divergentes (GODOY, 2016).

O recurso à história brasileira permite "[...] identificar permanências [atuais] de nosso passado autoritário e antidemocrático [...]" (GODOY, 2016 , p. 14), autorizando a defender a hipótese de que a onda conservadora atual reflete o autoritarismo arraigado, mesmo que enrustido, na sociedade 
brasileira. Essa última onda conservadora com explicitações fascistas eclode com as manifestações de 2016 pelo impeachment (GODOY, 2016) e se intensifica, abertamente, por discursos e atos, em manifestações de intolerância e violência contra as diversidades socioculturais (mulheres, negros, indígenas, homoafetivos), mas também, manifestações de violência de classe. Assim, concorda-se com Godoy quando afirma que "[...] o autoritarismo é um componente estrutural, multissecular, transversal no tempo. É o fundo do nosso oceano, a nossa região abissal" (GODOY, 2016, p. 36).

Em algumas conjunturas, o autoritarismo se intensifica, a exemplo da ditadura varguista, do regime militar (1964-1985) e, agora, se está vivendo um novo momento de seu recrudescimento.

Assim, é digno de destaque o clima conservador e antidemocrático que vem se instalando no País, bem como no campo da discussão educacional - tanto a básica quanto superior - e na própria universidade pública.

Nesse campo, é preciso destacar os recentes ataques a dirigentes universitários - na Universidade Federal do Rio Grande do Sul (UFRGS), com a "Operação PhD"; na Universidade Federal do Paraná (UFPR), com a "Operação Research"; na Universidade Federal de Santa Catarina (UFSC),com a ação 68 "Ouvidos moucos" e na Universidade Federal de Minas Gerais (UFMG), com a "Esperança equilibrista" - sem juízo condenatório definitivo. Um escarcéu repressivo e midiático é desencadeado antes e a apuração de responsabilidades vem depois. Normas básicas do direito como a presunção de inocência, o devido processo legal e a dignidade da pessoa humana são desprezadas. O clima policialesco e a mentalidade inquisitória parecem ter definitivamente suplantado uma cultura de direitos que valorizava a liberdade. Em nome de um certo moralismo administrativo e de uma sanha punitivista, garantias e direitos individuais são colocados como detalhes incômodos e inconvenientes. $\bigcirc$ princípio da autonomia universitária - prevista no art. 207 da Constituição -, por todas as razões, antes mencionadas, é reduzido a pó e a letra morta (FONSECA, 2017).

Após esse breve diagnóstico da situação econômica, política e cultural brasileira e da plataforma programática do atual governo, já em avançado curso, é pertinente indagar: quais os impactos, que já se podem visualizar, para a educação superior? 


\section{Educação superior na conjuntura de exceção: os diferentes modos de inserção da rede pública e da rede privada}

Oexame da atual conjuntura da educação superior brasileira constitui-se em notório desafio. Primeiramente, porque é bastante arriscado generalizar análises nesse campo, considerando que a educação superior brasileira é bastante diversificada e heterogênea, especialmente, no tocante à organização acadêmica, qualidade e inclusão social. Em segundo lugar, a análise da educação superior, na conjuntura atual, habita um terreno ardiloso, porque incide sobre um tempo presente muito especial e crítico, exposto, em linhas gerais, na primeira parte da apresentação, no qual se está completamente mergulhado e implicado (MANCEBO, 2017).

Não obstante as dificuldades do tema, têm-se início o seu desenvolvimento. Sabe-se que, no momento atual, o principal movimento que se verifica na educação superior brasileira diz respeito à "adaptação e acomodação" das instituições de educação superior (IES) à recessão e cortes sistemáticos, advindos da federação e de diversos entes federativos.

Na rede pública de educação superior

As consequências mais imediatas dessa conjuntura de ajuste fiscal, cuja prioridade absoluta tem sido o pagamento dos juros e encargos da dívida pública, são:

$1^{a}$ - $\bigcirc$ abandono da infraestrutura física dos campi, com interrupção de obras e a deteriorização das instalações já existentes são visíveis na maior parte das instituições de educação superior (IES) públicas. Esse quadro deve agravar em 2018, pelo menos, na rede federal, considerando que, os recursos para custeio, foram mantidos em patamar 20\% inferior aos valores de 2014 e os recursos para investimento foram ainda mais reduzidos, representando agora um corte de mais de $80 \%$ em relação a 2014 , conforme dados apresentados pela Sociedade Brasileira para o Progresso da Ciência (SBPC, 2017$).$

$2^{a}$ - $\bigcirc$ estancamento e a desaceleração do movimento de expansão de matrículas e cursos são, infelizmente, uma decorrência lógica do baixo investimento governamental, como podem ser apreciados na Tabela 1. 
A análise da série histórica apresentada indica que nunca houve um movimento de expansão de matrículas e cursos levado a cabo, sistematicamente. $\bigcirc$ caso do programa Reestruturação e Expansão das Universidades Federais (Reuni), que vigorou de 2007 a 2012, é um caso isolado e a série histórica apresentada indica, claramente, que essa onda expansionista, na realidade, foi refreada antes do golpe.

Como pode ser visualizado, a partir de 2013, a expansão de matrículas cessa, o que compromete o direito à educação, além de deixar às instituições a amarga tarefa de reconfigurar diversos procedimentos internos, para atender à expansão (do período anterior) que thes legou mais alunos, cursos, campi e forte interiorização, sem financiamento para a devida consolidação (MANCEBO; SILVA JÚNIOR; OLIVEIRA, 2018).

\section{Tabela 1}

Evolução das matrículas dos cursos de graduação presenciais e a distância no Brasil, na rede pública, 1995-2016

\begin{tabular}{|c|c|c|c|}
\hline Ano & $\begin{array}{c}\text { Matrí́culas nas IES } \\
\text { Públicas }\end{array}$ & $\begin{array}{c}\text { \% Matrículas } \\
\text { Públicas }\end{array}$ & $\begin{array}{c}\% \text { Anual das } \\
\text { Matrí́culas } \\
\text { Públicas }\end{array}$ \\
\hline 1995 & 700.540 & $40 \%$ & \\
\hline 1996 & 735.427 & $39 \%$ & $5 \%$ \\
\hline 1997 & 759.182 & $39 \%$ & $3 \%$ \\
\hline 1998 & 804.729 & $38 \%$ & $6 \%$ \\
\hline 1999 & 832.022 & $35 \%$ & $3 \%$ \\
\hline 2000 & 888.708 & $33 \%$ & $7 \%$ \\
\hline 2001 & 944.584 & $31 \%$ & $6 \%$ \\
\hline 2002 & 1.085 .977 & $31 \%$ & $15 \%$ \\
\hline 2003 & 1.176 .174 & $30 \%$ & $8 \%$ \\
\hline 2004 & 1.214 .317 & $29 \%$ & $3 \%$ \\
\hline 2005 & 1.229 .332 & $27 \%$ & $1 \%$ \\
\hline 2006 & 1.247 .733 & $26 \%$ & $1 \%$ \\
\hline 2007 & 1.281 .203 & $24 \%$ & $3 \%$ \\
\hline 2008 & 1.552 .953 & $27 \%$ & $21 \%$ \\
\hline 2009 & 1.523 .864 & $26 \%$ & $-2 \%$ \\
\hline
\end{tabular}




\section{Tabela 1}

Evolução das matrículas dos cursos de graduação presenciais e a distância no Brasil, na rede pública, 1995-2016 (Continuação)

\begin{tabular}{|c|c|c|c|}
\hline Ano & $\begin{array}{c}\text { Matrículas nas IES } \\
\text { Públicas }\end{array}$ & $\begin{array}{c}\% \text { Matrículas } \\
\text { Públicas }\end{array}$ & $\begin{array}{c}\text { \% Anual das } \\
\text { Matrículas } \\
\text { Públicas }\end{array}$ \\
\hline 2010 & 1.643 .298 & $26 \%$ & $8 \%$ \\
\hline 2011 & 1.773 .315 & $26 \%$ & $8 \%$ \\
\hline 2012 & 1.897 .376 & $27 \%$ & $7 \%$ \\
\hline 2013 & 1.932 .527 & $26 \%$ & $2 \%$ \\
\hline 2014 & 1.961 .002 & $25 \%$ & $1 \%$ \\
\hline 2015 & 1.952 .145 & $24 \%$ & $0 \%$ \\
\hline 2016 & 1.990 .078 & $25 \%$ & $2 \%$ \\
\hline
\end{tabular}

Fonte: BRASIL/MEC/INEP, 1996 a 2017.

$3^{a}-\bigcirc$ uso de estratégias diversas de desregulamentação e ataque aos direitos trabalhistas é, decididamente, uma das principais consequências das políticas de ajuste na educação superior.

A dramática história recente da Universidade do Estado do Rio de Janeiro (UERJ) ilustra e dá o tom do que está a acontecer. Começou em 2015, com cortes no custeio e investimento, teve continuidade, em 2016, com parcelamento de salários e demissões em massa de terceirizados, culminando em 2017, com atrasos salariais e de bolsas que chegaram a cinco meses. Outros estados da federação fazem exercícios semelhantes. Nas instituições federais, a crise agudiza-se, progressivamente, também desde 2014. Adicionalmente, com a legislação trabalhista aprovada após o golpe, a situação agrava-se.

Uma situação que vem se generalizando e que está a requerer investigações mais aprofundadas refere-se à terceirização da força de trabalho auxiliar - mas que poderá ser estendida para os trabalhadores das atividades fins, [em especial após a aprovação da Lei no 13.429, de 31 de março de 2017 (BRASIL, 2017) que garante, dentre outros aspectos, a terceirização irrestrita] - com contratos com empresas que negam aos funcionários, inclusive, direitos trabalhistas básicos e proteção (MANCEBO, 2017, p. 885). 
$4^{a}$ - Outro movimento, já perceptível em algumas IES públicas, refere-se a certo enxugamento de suas funções, priorizando-se o ensino (como é o caso dos Institutos Federais de Educação, Ciência e Tecnologia - IFs), comprometendo o preceito institucional da indissociabilidade entre ensino, pesquisa e extensão.

$5^{a}-\bigcirc$ ensino, por seu turno, muitas vezes, tem sido aligeirado, voltado às exigências de mercado ou desenvolvido mediante o uso apressado e aligeirado do ensino a distância (EAD), que já alcançava em torno de 6\% das matrículas, nas IES públicas, em 2016. Adicionalmente, a formação nem sempre se encontra adaptada às necessidades dos novos estudantes que adentraram a universidade pública, criando sérios problemas de evasão.

$6^{a}$ - No que tange à produção do conhecimento, os cortes também têm sido significativos.

Apesar do esforço e da pressão da comunidade científica nacional, a Lei Orçamentária Anual (LOA) de 2018 - Lei n 13.587, de 2 de janeiro de 2018 (BRASIL, 2018) - foi sancionada pelo presidente Michel Temer, com o orçamento geral de R\$12,7 bilhões para o Ministério da Ciência, Tecnologia, 72 Inovações e Comunicações (MCTIC), 19\% a menos que o valor sancionado na LOA de 2017, conforme denunciaram diversas entidades científicas, em recente Manifesto:

[...] [os] sérios cortes ocorreram também em agências, universidades públicas e instituições de pesquisa ligadas a outros ministérios. Os recursos para a CAPES [Coordenação de Aperfeiçoamento de Pessoal de Nível Superior] em 2018, uma agência fundamental para a pós-graduação brasileira, responsável por grande parte da pesquisa científica produzida no país, terão uma diminuição de 20\% em relação ao aprovado para o orçamento de 2017. [...]

Não aceitamos como justificativa a crise econômica e fiscal, [pois], como demonstram dados governamentais e tem sido amplamente divulgado na mídia, estão ocorrendo desonerações e isenções fiscais em inúmeras áreas, que vão de bancos privados a empresas petrolíferas estrangeiras, e cujos valores são pelo menos uma centena de vezes maiores do que o solicitado para CT\&l [Ciência, Tecnologia e Inovação] (SBPC, 2017, s.p.).

Mas, os impactos não param aí, pois a própria identidade da produção do conhecimento tem sido profundamente afetada. E isto porque, nesse 
campo, há uma forte tendência que tenta vincular, organicamente, a produção de conhecimento às cadeias produtivas locais, nacionais e mundializadas. De fato, já é verificável, em alguns grupos e instituições "de ponta", a indução da própria pauta de investigação, o que implica dizer que a pesquisa, fortemente realizada na pós-graduação, tende a se orientar pela economia (SILVA JÚNIOR, 2017; LANDER, 2005). "Assim, a ciência e a atividade de investigação universitária não escapam dos avanços da lógica mercantil que invade, progressivamente, mais e mais âmbitos da vida coletiva" (MANCEBO, SILVA JÚNIOR, OLIVEIRA, 2018 , s.p.).

$7^{a}$ - $\bigcirc$ fim da gratuidade no ensino de graduação é outro risco concreto. Ele foi postulado, explicitamente, no ano passado, por duas frentes políticas, aparentemente, distintas.

Em outubro de 2017, o deputado Andres Sanchez (PT-SP) propõe a PEC n 366, de 4 de outubro de 2017 (BRASIL, 2017), que foi retirada da pauta por pressão do próprio Partido.

Em novembro, o Banco Mundial (2017) entrega ao atual Ministro Henrique Meirelles, um relatório encomendado pelo ex-Ministro Joaquim Levy, um estudo que, entre outros aspectos, propõe a cobrança de mensalidades nas IES públicas brasileiras. $O$ documento é bastante detalhado, mas pleno de falhas técnicas, por exemplo, quando afirma que os alunos da universidade pública brasileira sejam ricos; que a maioria dos estudantes que frequentam as universidades públicas no Brasil tenha frequentado escolas primárias e secundárias privadas e caras ou, ainda, quando argumenta que a universidade pública seja ineficiente porque gasta 2 a 3 vezes mais que as privadas.

Pesquisa coordenada pela Associação Nacional dos Dirigentes das Instituições Federais de Ensino Superior (ANDIFES, 2017) sobre o perfil social de estudantes de universidades federais revela, ao contrário do Banco Mundial, que somente $10 \%$ dos alunos matriculados nas universidades federais vêm de famílias com renda bruta familiar de dez ou mais salários mínimos. Na outra ponta, $51 \%$ dos alunos das universidades federais pertencem a famílias com renda bruta abaixo de três salários mínimos. Se considerada a renda média per capita, 78\% dos alunos são de famílias com renda per capita de até dois salários mínimos. Não há, portanto, fundamento para a afirmação de que os alunos das universidades federais pertencem aos estratos de renda mais altos 
da sociedade, muito menos que possuem capacidade financeira para pagar mensalidades.

Adicionalmente, o argumento do Banco Mundial de que a universidade pública gasta mais do que as IES privadas é, no mínimo, irresponsável. Não cabe a comparação do custo aluno das IES públicas e das privadas, pois, diferentemente das instituições privadas, a universidade pública brasileira abrange, além do ensino superior, o oferecimento de ensino em outros níveis, a manutenção de hospitais universitários, laboratórios, museus, teatros, estádios de esporte e uma série de outras instalações em que professores, técnicos e estudantes podem conviver. Além de todos esses serviços, as universidades públicas são responsáveis por quase toda a pesquisa científica e tecnológica realizada no país.

Para finalizar esse item, com certeza, defende-se que se cobre mais dos mais ricos, mas não com o pagamento de mensalidades. Nesse campo, o que é preciso é uma reforma tributária que permita tratamento isonômico aos contribuintes, a criação de um imposto sobre fortunas e o aumento da taxação de heranças, conforme argumenta a Andifes (2017):

[...] é verdade que os mais ricos deveriam pagar pela educação pública, mas não apenas os mais ricos que têm filhos nas universidades públicas. Uma política distributiva séria tributaria todos os ricos (com ou sem filhos nas universidades públicas) taxando fortunas, heranças e propriedades, a fim de possibilitar a parcelas maiores da população o acesso à educação pública de qualidade (ANDIFES, 2017, s.p.).

\section{A rede privado-mercantil de educação superior}

Pode-se afirmar que, para as IES privadas, que detinham $75 \%$ das matrículas em cursos de graduação em 2016, os efeitos da crise e dos ajustes não são os mesmos (MANCEBO; SILVA JÚNIOR; OLIVEIRA, 2018).

De fato, ocorreu uma diminuição no ritmo de evolução das matrículas nas instituições privadas do ensino superior, nos últimos anos. Conforme dados do Censo da Educação Superior do Inep (2014, 2015, 2016 e 2017), o comportamento das matrículas na rede privada foi o seguinte: em 2013, há um crescimento de 4,54\%; em 2014 de 9,19\%, em 2015 de 3,55\% e em 2016, 
há um decréscimo de - 0,27\%. Assim, a crise só se faz visível no setor a partir de 2015, sendo que, em 2016, chega a ocorrer um decréscimo no número de matrículas. Mas esse dado não é o único, nem o melhor indicador da situação dessas IES.

Não se pode esquecer que se está lidando com uma fração do empresariado brasileiro fortemente organizado, articulado e ágil e já se pode verificar algumas saídas que essas instituições vêm desenvolvendo para o enfrentamento da crise.

Primeiramente, operaram mudanças organizacionais/denominadas governança corporativa) que diminuem as despesas, como o enxugamento do quadro de trabalhadores, o aumento do número de alunos por turma, a modificação de currículos, suprimindo disciplinas onerosas, o rearranjo de turmas, na maior parte das situações sob o olhar complacente do MEC.

Um quesito que merece destaque refere-se ao uso do ensino a distância que, pelo último Censo da Educação Superior do Inep (BRASIL, 2017) já alcançava 23\% das matrículas desse setor no ensino de graduação. Conforme recente matéria, publicada pela Agência Brasil, o ensino a distância cresce mais, na rede privada, do que o presencial e, "[...] seguindo o ritmo atual, a modalidade a distância [...] deve superar o ensino presencial em 2023" (TOKARNIA, 2018, s.p.).

Essas práticas têm levado as IES privadas - quase todas descomprometidas com a qualidade do ensino, com a formação profissional e menos ainda com a ética nas relações de trabalho - a tratar a educação como mercadoria, e o trabalhador como um "custo"5.

Com a entrada em vigor da Reforma Trabalhista (Lei n 13.467, de 13 de julho de 2017) e da Lei da Terceirização (Lei n 13.429, de 31 de março de 2017$)$, que desconstroem a Consolidação das Leis do Trabalho (CLT), tem-se como resultado a efetivação de demissões em massa ocorridas no ensino superior privado, em finais de $2017^{6}$. Conforme análise de Sousa (2017):

[...] o alcance da mercantilização do ensino superior, potencializada pela contrarreforma do mundo do trabalho, já se concretiza, com o sucateamento das relações de trabalho, o fechamento de postos e com o aprofundamento de uma educação massificada, porém vazia de significado socialmente referenciado ISOUSA, 2017 , s.p.). 
Adicionalmente, essa fração da burguesia possui uma larga experiência de lobbies, junto ao Congresso e governos. Isso tem possibilitado uma potente indução estatal. Assim, seu crescimento foi fomentado, sobretudo, por programas de subsídios - Fundo de Financiamento Estudantil (Fies) e Programa Universidade para Todos (Prouni) -, além das generosas políticas de negociação de dívidas, como a oferecida pelo Programa de Estímulo à Reestruturação e ao Fortalecimento das Instituições de Ensino Superior (Proies).

Conforme dados apresentados por Reis (2018), em 2017, o governo federal liberou $R \$ 21,82$ bilhões para o Fies e o Prouni e o que é mais surpreendente é que essas despesas passaram a representar, aproximadamente, $16,74 \%$ do orçamento total sob a supervisão do MEC. De fato, o número de novos contratos do Fies caiu muito de 2014 para 2017, como amplamente noticiado pela grande imprensa. De acordo com o Portal do Fundo Nacional de Desenvolvimento da Educação (FNDE), enquanto em 2014, havia um total de 731.700 novos contratos, em 2016, esse número foi somente de 203.392 novos contratos (FNDE, 2017). Todavia, em termos de recursos destinados pela União, o aumento dos repasses permaneceu como tendência, passando de R\$1 5 bilhões de reais, em 2014, para R\$20,47 bilhões, em 2017 (REIS, 2018).

Conforme analisado por Mancebo, Silva Júnior e Oliveira:

[...] mesmo nesse contexto de crise no financiamento das IES públicas e de restrição aos direitos da classe trabalhadora e da população, o governo federal permanece adotando medidas que enfraquecem os mecanismos de controle e favorecem o crescimento das IES privado-mercantis, em especial os grandes grupos empresariais que, a partir de 2007, ingressaram no mercado de ações (MANCEBO, SILVAJÚNIOR E OLIVEIRA, 2018 , s.p.).

Chega-se, então, ao ponto central para a análise desses grupos: seu desempenho na bolsa de valores. Desde 2007, abriram seus capitais, e o período que, vai de 2008 a 2013, é o ápice desse processo, de modo que hoje se está diante de um setor fortemente financeirizado, cujas ações são altamente rentáveis. Desde então, a lógica dos negócios passa a ser a da "maximização do lucro para o acionista" (GUTTMANN, 2008, p. 12), qual seja, "[...] ocorre um esforço contínuo em alinhar os objetivos da administração dessas empresas educacionais aos interesses dos acionistas, através da adoção de práticas 
mais justas, proporcionando maior liquidez e melhor valorização das ações negociadas no mercado" (MANCEBO; SILVA JÚNIOR; OLIVEIRA, 2018, s.p.).

Trabalha-se, portanto, com a hipótese (praticamente conclusiva) de que esses grupos são suficientemente "criativos" para o enfrentamento da complexa conjuntura brasileira e que não estão sofrendo os impactos do ajuste financeiro, com o mesmo rigor que o setor público.

\section{Considerações Finais}

Este artigo apresentou alguns dos principais impactos das políticas de ajuste, aprofundadas com o golpe de 2016, na educação superior brasileira. Nele defende-se a hipótese de que tais impactos são bem distintos, senão opostos, quando se considera a rede pública e a privada. Resta tecer considerações sobre alguns desafios que a atual conjuntura impõe, para sua superação e a defesa da educação pública.

No que tange ao financiamento, é preciso ter a clara compreensão de que o orçamento público não é uma peça 'técnica' (mera previsão da arrecadação de receita se da alocação de despesas). Ele é o resultado de decisão política do poder executivo e legislativo. Parcelas significativa do Orçamento da União $(45,1$ 1\%, em 2015$)$ tem sido utilizada para pagar despesas com a dívida pública, o que acarreta uma redução de recursos disponíveis ao financiamento da educação, da ciência e tecnologia e de outras políticas sociais (REIS, 2018 , s.p.). Essa tendência precisa ser revertida, deve ser alvo de disputa e de lutas.

No que tange às IES, faz-se necessário, primeiramente, avançar na ampliação do acesso, obviamente nas IES públicas, pois ele se encontra muito aquém das demandas territoriais, demográficas, raciais e etárias da população brasileira. Em seguimento, permanece o desafio de superar estatísticas alarmantes referentes ao tema, como analisado por Mancebo, Silva Júnior e Oliveira (2018):

O Observatório do Plano Nacional de Educação (OBSERVATÓRIO DO PNE, 2017 ), baseado na Pesquisa Nacional por Amostra de Domicílios do IBGE, indica que, em 2015, somente 18,1\% da população brasileira de 18 a 24 anos (taxa líquida) estavam matriculados na educação superior (incluindo a pós-graduação); a taxa 
líquida de matrícula na educação superior das populações rurais era de 6,5\%; a taxa líquida do quartil mais rico era de $41,5 \%$ e do quartil mais pobre da população de somente $6,9 \%$ e, por fim, a vergonhosa desigualdade que nos indica que a taxa líquida de matrícula na educação superior da população branca era quase o dobro das taxas das populações negras e indígenas (MANCEBO; SILVAJÚNIOR; OLIVEIRA, 2018 , s.p.).

Em relação à permanência, é preciso discutir e propor políticas públicas que garantam a terminalidade dos estudantes, em especial, aqueles advindos das classes subalternas, mas também constituir práticas de igualdade, respeito às diversidades e relações solidárias e de fraternidade.

Quanto à produção do conhecimento, é preciso tornar as IES relevantes tanto em termos sociais quanto em termos científicos, e para tal "[...] urge uma reconciliação dos seus intelectuais com o conhecimento crítico, reflexivo e, por isso mesmo, insubmisso aos interesses mercantis e antidemocráticos [...]" (MANCEBO, 2017, p. 888), o que exige o debate democrático sobre a própria gestão da universidade, da ciência e da tecnologia. Assim, deve-se perguntar, diuturnamente, para quem se pretende destinar os conhecimentos 78 e saberes produzidos na universidade? Para erigir que tipo de sociedade tais conhecimentos e saberes devem ser direcionados?

Para as ciências humanas e sociais, os desafios são maiores, pois precisam cumprir um papel mais ativo e decisivo, rompendo com seus limites teóricos, suas especialidades estanques, suas cadeias conceituais, determinadas por preconceitos ideológicos e por seus compromissos com os interesses conservadores (SANTOS, 1987). Pode-se e deve-se dar provas à humanidade, para que ela reconheça conceitual e praticamente, sobre a inviabilidade de uma ordem econômica mundial que divide os homens entre bilhões (cujo número cresce a cada dia) de miseráveis e alguns mil, cuja riqueza irracional já compromete a sobrevivência do universo lameaça de escassez de energia, rompimento da camada de ozônio, destruição de espécies animais e vegetais e outras formas de vida, alterações drásticas do clima, entre outros aspectos).

Conforme argumentado em um texto anterior, em face desses desafios, há que se considerar que a problemática da educação superior na atual conjuntura, especialmente, nos países que não compõem o centro do capitalismo, como o Brasil, é de reversão bastante complexa. Não mudará sem uma profunda reforma de seus espaços estritamente acadêmicos - e para tal, 
o empenho e criatividade são vitais -, mas tampouco mudará, contando apenas com os protagonistas diretos da universidade, os professores, técnicos, funcionários administrativos e os estudantes (MANCEBO, 2017). Assim, há que se levar mais a sério a tese desenvolvida por Roberto Leher de que "[...] sem os movimentos sociais antissistêmicos a defesa de um lugar estratégico para a universidade pública, crítica e autônoma [e libertária] no projeto de nação permanecerá débil e, possivelmente, inviável" (LEHER, 2015, p. 4).

Por fim, há que se pensar o Brasil. Discute-se a inevitabilidade da saída do governo Temer e a importância das eleições de 2018, o que dependerá da organização, radicalidade e coerência programática dos que se opõem ao atual Estado de Exceção. Todavia, no momento em que esse texto é escrito, é grande o risco de as eleições serem apenas um mecanismo de institucionalização do golpe, isto é, de dar-the uma fachada de legalidade, e podem até ser inviabilizadas. Assim considerando ...

[...] seja qual for o rumo da história, não se pode apostar tão somente em eleições, pois assim persiste-se no erro de supervalorização da políitica institucional, renunciando ao poder que pode de fato mudar, restaurando os procedimentos mínimos da democracia e de um campo de luta pela justiça social, que é aquele construído nas ruas e nas organizações populares (MANCEBO; SILVA JÚNIOR; OLIVEIRA, 2018 , s.p.).

Urge, portanto, discutir amplamente e construir um programa contra-hegemônico, um programa para as próximas décadas, que seja capaz de organizar a esperança, contra o capital. Um programa que contemple amplas políticas de inclusão, bem como políticas de classe, pois a "sociedade brasileira é uma sociedade capitalista, racista e sexista, é extremamente desigual e violenta" (SANTOS, 2018 , s.p.). Mas, recolhendo lições da história recente, é preciso ter a consciência de ultrapassar a política de conciliação de classes (o lulismo) e de que, nesse campo e com essa radicalidade, não há espaço para avançar sem conflito e enfrentamento.

Para finalizar, cabe o registro das lúcidas palavras de Clemente Ganz Lúcio (2017), Diretor Técnico do Dieese, pois traduzem, com muita pertinência, o que se deseja transmitir nessas considerações finais, ecoam, fazendo pensar e agir: 
A história das conquistas sociais e políticas, impulsionadas pela utopia da justiça, da liberdade e da igualdade, indica que não há uma alternativa a não ser lutar, depois, lutar e, por fim, lutar! E se a esperança estiver se esvaindo, o cansaço se sobressaindo, as costas doídas de tantos embates, será preciso olhar para o lado, reconhecer os companheiros e companheiras, pedir ajuda e, na solidariedade que há séculos une os trabalhadores como classe, cerrar as fileiras que nos tornam imbatíveis (LÚClO, 2017, s.p.).

\section{Notas}

1 texto foi apresentado, no dia 5 de fevereiro de 2018, na palestra de abertura do Seminário de Avaliação e Planejamento do Centro de Educação da Universidade Federal do Rio Grande do Norte, sobre o tema "O desmonte das Universidades Públicas e os desdobramentos para as políticas educacionais".

2 "A taxa de desocupação do trimestre encerrado em março de 2018 chegou a 13,1\%, com aumento de 1,3 ponto percentual em relação ao último trimestre do ano passado (1 1,8\%). $\bigcirc$ total de pessoas desocupadas também cresceu no período, passando de 12,3 milhões para 13,7 milhões. Houve um aumento de 11,2\% nesse contingente, ou mais 1,4 milhões de desempregados no país" (IBGE, 2018, s.p.).

3 Agamben define "Estado de Exceção" a partir de um paradigma que desenvolve "uma zona de anomia que, de um lado, deve ser mantida a todo custo em relação com o direito e, de outro, deve ser

80 também implacavelmente libertada dessa relação" (AGAMBEN, 2004, p. 92). Deve-se registrar que, no Brasil, essa zona de anomia foi construída a partir da ampliação do número de normas em várias áreas do Direito.

4 Projeto de Lei no 193 de 2016 (BRASIL, 2016), que instituiria o programa Escola sem Partido, foi retirado, em finais de novembro de 2017, definitivamente, da pauta do Senado Federal, mas há vários processos semelhantes ocorrendo nas Assembleias Estaduais e Câmaras Municipais.

5 Sguissardi (2015, p. 1 14) destaca o papel dos fundos de investimento privado, transnacionais, no "preparo" das primeiras empresas brasileiras que visavam abrir o capital e fazer oferta pública inicial de ações na bolsa. Eles investiram altas quantias em empresas educacionais, induziram processos de reestruturação, visando à racionalização administrativa e ao uso de gestão empresarial.

6 Só para citar um exemplo: em 5 de dezembro de 2017, a Estácio anunciou que demitiria 1200 professores e contrataria outros tantos por um novo regime de trabalho.

\section{Referências}

AGAMBEN, Giorgio. Estado de exceção. São Paulo: Boitempo, 2004.

ANDIFES. As universidades federais são mais eficientes que o Banco Mundial. 2017.

Disponível em: http://www.andifes.org.br/universidades-federais-sao-mais-eficientes-que-o-banco-mundial. Acesso em: 15 jan. 2018. 
BANCO MUNDIAL. Um ajuste justo: análise da eficiência e equidade do gasto público no Brasil. 2017. Disponível em: http://documents.worldbank.org/curated/ pt/88487151 $1196609355 /$ pdf/ 121 480-REVISED-PORTUGUESE-Brazil-Public-Expenditure-Review-Overview-Portuguese-Final-revised.pdf. Acesso em: 15 dez. 2017.

BRASIL. Projeto de Lei $\mathbf{n}^{\circ}$ 193, de 2016. Inclui entre as diretrizes e bases da educação nacional, de que trata a Lei n 9.394, de 20 de dezembro de 1996, o "Programa Escola sem Partido". Disponível em: https://www25.senado.leg.br/web/atividade/materias/-/ materia/125666. Acesso em: 10 jan. 2018.

Proposta de Emenda Constitucional $\mathbf{n}^{\circ}$ 287, de 5 de dezembro 2016. Altera os arts. 37, 40, 109, 149, 167, 195, 201 e 203 da Constituição, para dispor sobre a seguridade social, estabelece regras de transição e dá outras providências. Disponível em: https://www.camara.gov.br/proposicoesWeb/prop_mostrarintegra?.codteor=1527338 \&filename $=E M C+3 / 2017+P E C 28716+\% 3 D \% 3 E+P E C+287 / 2016$. Acesso em: 10 jan. 2018.

Emenda Constitucional $\mathrm{n}^{\circ}$ 95, de 15 de dezembro de 2016. Altera $\circ$ Ato das Disposições Constitucionais Transitórias, para instituir o Novo Regime Fiscal, e dá outras providências. Disponível em: http://www.planalto.gov.br/ccivil_03/constituicao/emendas/ emc/emc95.htm. Acesso em: 15 fev. 2018.

Lei $\mathbf{n}^{\circ}$ 13.429, de 31 de março de 2017. Altera dispositivos da Lei n 6.019, de 3 de janeiro de 1974, que dispõe sobre o trabalho temporário nas empresas urbanas e dá outras providências; e dispõe sobre as relações de trabalho na empresa de prestação de serviços a terceiros. Disponível em: http://www. planalto.gov.br/ccivil_03/_ato2015$2018 / 2017 /$ lei/L13429.htm. Acesso em: 15 fev. 2018.

Lei $\mathbf{n}^{\circ}$ 13.467, de 13 de julho de 2017. Altera a Consolidação das Leis do Trabalho (CLT), aprovada pelo Decreto-Lei $n^{\circ} 5.452$, de $1^{\circ}$ de maio de 1943, e as Leis nos 6.019, de 3 de janeiro de 1974, 8.036, de 11 de maio de 1990, e 8.212, de 24 de julho de 1991, a fim de adequar a legislação às novas relações de trabalho. Disponível em: http:// www.planalto.gov.br/ccivil_03/_ato2015-2018/2017/lei/l13467.htm. Acesso em: 15 fev. 2018.

Proposta de Emenda Constitucional n ${ }^{\circ}$ 366, de 4 de outubro de 2017. Trata de ensino superior pago em instituição de ensino superior pública. Disponível em: http://www. camara.gov. br/proposicoesWeb/fichadetramitacao?idProposicao=2155185. Acesso em: 15 fev. 2018. 
Lei $\mathbf{n}^{\circ}$ 13.587, de 2 de janeiro de 2018. Estima a receita e fixa a despesa da União para o exercício financeiro de 2018. Disponível em: http://www.planalto.gov.br/ ccivil_03/_ato2015-2018/2018/lei/L13587.htm. Acesso em: 15 fev. 2018.

BRASIL. MEC. INEP. Sinopses estatísticas do Censo da Educação Superior: 1995 a 2017. Brasilia: MEC. Disponível em: hitp://www.inep.gov.br/superior/censosuperior/sinopse/ default.asp. Acesso em: 10 jan. 2018.

FONSECA, Ricardo Marcelo. Um ano de ataques contra as universidades públicas brasileiras. 2017. Disponível em: http://www.andifes.org.br/ufpr-um-ano-de-ataques-contra-universidades-publicas-brasileira/. Acesso em: 15 fev. 2018.

FUNDO Nacional de Desenvolvimento da Educação (FNDE). Financiamentos concedidos. Brasília: 2017. Disponível em: http://www.fnde.gov.br/financiamento/fies/mantenedoras-e-ies/financiamentos-concedidos-fies. Acesso em: 15 fev. 2018.

GODOY, Rosa Maria. A fascistização da sociedade brasileira. In: ENCONTRO ESTADUAL DE HISTÓRIA DA ASSOCIAÇÃO NACIONAL DE HISTÓRIA, 17; 2016, Guarabira, Paraíba. Anais... Natal: Universidade Federal do Rio Grande do Norte, 2016.

GUTTMANN, Robert. Uma introdução ao capitalismo dirigido pelas finanças. Novos Estudos 82 Cebrap, São Paulo, v. 27, n. 3, nov. 2008. Disponível em: http://www.scielo.br/scielo. php? script=sci_arttext\&pid=S0 $101-33002008000300001$ \&lng=pt\&nrm=isso. Acesso em: 15 jan. 2018.

IASI, Mauro Luis. A esfinge que nos devora: os desafios da esquerda brasileira. 2017. Disponível em: http://marxismo21.org/wp-content/uploads/2017/05/Mauro-lasi-Aesfinge-que-nos-devora-as-perspectivas-na-esquerda-no-Brasil-1.pdf. Acesso em: 26 jan. 2018.

IBGE. Desemprego volta a crescer no primeiro trimestre de 2018. 2018. Disponível em: https://agenciadenoticias. ibge.gov.br/agencia-noticias/2012-agencia-de-noticias/ noticias/20995-desemprego-volta-a-crescer-no-primeiro-trimestre-de-2018.html. Acesso em: 26 jan. 2018.

LANDER, Edgardo. La ciencia neoliberal. Revista Venezolana de Economía y Ciencias Sociales, Caracas, v. 11 , n. 2, maio/ago. 2005. Disponível em: http://www.scielo.org. ve/scielo.php?script=sci_arttext\&pid=S1 31 5-64112005000200003. Acesso em: 15 jan. 2018.

LEHER, Roberto. Movimentos sociais, padrão de acumulação e crise da universidade. In: REUNIÃO NACIONAL DA ANPED, 37; 2015, Florianópolis. Anais... Florianópolis: 
Associação Nacional de Pós-graduação e Pesquisa em Educação, 2015. Disponível em: http://37reuniao. anped.org.br/wp-content/uploads/2015/02/Trabalho-de-RobertoLeher-para-o-GT1 1.pdf. Acesso em: 15 dez. 2017.

LÚCIO, Clemente Ganz. Os sindicatos brasileiros saberão se reinventar? 2017. Disponível em: http://outraspalavras.net/outrasmidias/capa-outras-midias/os-sindicatos-brasileiros-saberao-se-reinventar/. Acesso em: 15 dez. 2017.

MANCEBO, Deise. Crise político-econômica no Brasil: breve análise da educação superior. Educação \& Sociedade, Campinas, v. 38, n. 139, p. 875-892, out./dez. 2017. Disponível em: http://www.scielo.br/scielo.php?script=sci_arttext\&pid=S0101$-73302017005005105 \&$ lng=pt\&nrm=isso. Acesso em: 15 jan. 2018.

MANCEBO, Deise; SILVA JúNIOR, João dos Reis; OLIVEIRA, João Ferreira de. Políticas, gestão e direito a educação superior: novos modos de regulação e tendências em construção. Acta Scientiarum Education, Maringá, v. 40, n. 1, jan./mar. 2018 . Disponível em: http:// periodicos.vem.br/ojs/index.php/ActaSciEduc/article/view/37669. Acesso em: 30 jan. 2018.

MARIANO, Cynara Monteiro. Emenda constitucional n 95/2016 e o teto dos gatos públicos: Brasil de volta ao estado de exceção econômico e ao capitalismo do desastre. Revista de Investigações Constitucionais, Curitiba, v. . 4, n. 1, p. 259-281, jan./abr. 2017.

OBSERVATÓRIO DO PNE. Educação superior. 2017. Disponível em: http://www.observatoriodopne.org.br/metas-pne/12-ensino-superior. Acesso em: 15 jan. 2018.

PMDB. Uma ponte para o futuro. São Paulo: Fundação Ulysses Guimarães, 2015.

POMAR, Valter. Cenário internacional. Blog Valter Pomar, 7 dez. 2016. Disponível em: http://valterpomar.blogspot.com.br/2016/12/cenario-internacional.html. Acesso em: 25 jan. 2018.

REIS, Luiz Fernando. Dívida pública e política econômica: o financiamento da educação superior e da ciência e tecnologia no Brasil (2003-2017). In: REUNIÃO CRAPUFPR, 1; 2018, Curitiba (datilografado).

SANTOS, Boaventura de Souza. Boaventura: Mensagem aos democratas brasileiros. Blog da Boitempo, 2018. Disponível em: https://blogdaboitempo.com.br/2018/01/26/boaventura-mensagem-aos-democratas-brasileiros/. Acesso em: 10 maio 2018.

SANTOS, Theotônio dos. Revolução científico-técnica e acumulação de capital. Petrópolis: Vozes, 1987. 
SBPC. Orçamento de CT\&I para 2018: tragédia anunciada! 2017. Disponível em: http:// portal.sbpcnet.org.br/noticias/orcamento-de-cti-para-2018-tragedia-anunciada/. Acesso em: 10 jan. 2018.

SGUISSARDI, Valdemar. Estudo diagnóstico da política de expansão da (e acesso à) educação superior no Brasil: 2002-2012. Piracicaba: 2015 (datilografado).

SILVA JÚNIOR, João dos Reis. The new Brazilian university: a busca por resultados comercializáveis: para quem? Marília: Projeto Editorial Práxis, 2017.

SINGER, André; LOUREIRO, Isabel (Org.). As contradições do lulismo: a que ponto chegamos? São Paulo: Boitempo, 2016.

SOUSA, Andrea Harada. Ensino mercantil e demissão em massa de professores no ensino superior privado. Le Monde Diplomatique Brasil, 22 dez. 2017. Disponível em: https:// diplomatique.org. br/ensino-mercantil-e-demissao-em-massa-de-professores-no-ensino-superior-privado/. Acesso em: 10 jan. 2018.

TOKARNIA, Mariana. Educação a distância cresce mais que presencial, mas não é $1^{a}$ opção. Agência Brasil, Brasília, 22 maio 2018. Disponível em: http://agenciabrasil. ebc.com.br/educacao/noticia/201 8-05/ensino-a-distancia-no-brasil. Acesso em: 23 maio 842018

Prof. ${ }^{a}$ Dr. ${ }^{a}$ Deise Mancebo Universidade do Estado do Rio de Janeiro Instituto de Psicologia Programa de Pós-graduação em Políticas Públicas e Formação Humana (PPFH/UERJ) Coordenadora da Rede Universitas/Br E-mail: deise.mancebo@gmail.com Recebido 12 jun. 2018 Aceito 24 ago. 2018 